\title{
Hospitalization trends for paediatric asthma in eastern Finland: a 10-yr survey
}

\author{
K. Korhonen*, T.M. Reijonen*, K. Malmström\#, T. Klaukka", K. Remes*, M. Korppi*
}

Hospitalization trends for paediatric asthma in eastern Finland: a 10-yr survey. K. Korhonen, T.M. Reijonen, K. Malmström, T. Klaukka, K. Remes, M. Korppi. (C) ERS Journals Ltd 2002.

ABSTRACT: The prevalence of childhood asthma has increased during the past $20 \mathrm{yrs}$ in eastern Finland. The use of regular medication for asthma has, consequently, also risen at the same time. The aim of the present study was to assess how these factors have influenced hospitalization for asthma in children.

Data concerning the annual number of children aged $<16$ yrs treated for asthma, their number of hospital periods, and length of hospitalization were collected using patient-specific medical records for the years 1988-1997.

Admissions for asthma more than doubled (from 1.2 in 1,000 to 2.7 in 1,000) $(\mathrm{p}<0.001)$, whereas re-admissions decreased from $28.1 \%$ to $8.7 \%(\mathrm{p}<0.001)$ during the study period. The greatest increase was seen among children aged $<2$ yrs, whereas during recent years the admission rate among children aged $>2$ yrs has declined by one-third.

Despite the increased prevalence of asthma, the decline in admissions seen in all but the youngest children may, at least partly, be attributed to the decrease in re-admissions, resulting from the early onset and increased use of inhaled steroids. Eur Respir J 2002; 19: 1035-1039.
*Dept of Paediatrics, Kuopio University Hospital, Kuopio, \#Dept of Paediatrics, Hospital for Children and Adolescents, Helsinki University Central Hospital, Helsinki, Finland and Social Insurance Institution, Helsinki, Finland.

Correspondence: K. Korhonen, Dept of Paediatrics, Kuopio University Hospital, P.O.B 1777, FIN-70211 Kuopio, Finland.

Fax: 35817172410

E-mail: kaj.korhonen@uku.fi

Keywords: Admission, asthma, children, epidemiology, hospitalization, readmission

\section{Received: July 172001}

Accepted after revision December 21 2001

The present study was supported by the Finnish Cultural Foundation of Northern Savo, the Finnish AntiTuberculosis Association Foundation and the Viik's Foundation.
The prevalence of childhood asthma has increased during the last two decades in Finland, as well as in other Western countries [1-4]. In many countries, the increased prevalence has led to a rise in hospital care [5-11]. In contrast, the hospitalization rate for asthma decreased in the Göteborg area of Sweden during the last decade, despite a simultaneous doubling in the prevalence of asthma [12]. During the same period, admission rates stabilized around the Oslo area in Norway [13].

A probable explanation for this favourable trend may be the early introduction of anti-inflammatory therapy [12-15]. Moreover, two recently published population-based studies have suggested that inhaled anti-inflammatory therapy may be associated with a significantly lower risk of hospitalization and emergency dept visits in children with asthma [16-17]. These studies indicated that cromolyn and inhaled corticosteroids had similar effects on hospitalization risks. In contrast, children on inhaled steroids have been demonstrated to have a lower risk of hospitalization than those on cromones, even though the use of cromones has also been shown to reduce the risk of hospitalization for asthma [18].
To the best of the authors' knowledge, no studies have used an adequate number of patients and a sufficiently long-term follow-up time to examine population-based data on hospitalization trends for asthma from areas where cromones, cromolyn sodium or nedocromil are prescribed for major maintenance therapy. In particular, more data are required on readmission rates, which may better reflect the effectiveness of a regular therapy for asthma than first admissions [19].

The purpose of this study was to investigate $10-\mathrm{yr}$ hospitalization trends for paediatric asthma in eastern Finland, where cromones were prescribed as the firstline therapy in children with asthma until the mid 1990s. Special attention was given to changes in re-admission rates in relation to age.

\section{Patients and methods}

Patients aged $\leqslant 16$ yrs treated for an exacerbation of asthma in the Dept of Paediatrics, Kuopio University Hospital, between 1 January 1988-31 December 1997, were retrospectively identified from the hospital-discharge register according to the 
International Classification of Diseases (ICD)- 9 code numbers $493^{* *}$ (asthma bronchiale) up to 1995 , and ICD-10 J45* (asthma bronchiale), and J46 (status asthmaticus) from 1996 onwards. In all cases, the patient-specific medical records of the children were systematically reviewed. The criteria for asthma were confirmed, and data on age, sex, admission date, and duration of hospitalization were collected. Asthma was defined as being the third episode of expiratory obstruction diagnosed by a doctor. In addition, severe cases responding insufficiently to glucocorticosteroids, nebulized sympathomimetics, and nebulized anticholinergics during hospital care were regarded as having asthma and included in the study regardless of previous history. To cover all asthma cases, hospitalization periods registered as codes commonly used for first and second obstructions (obstructive bronchitis, ICD-9 466** and ICD-10 J21.9) were also reviewed and included if the aforementioned criteria for asthma were fulfilled.

Kuopio University Hospital is the only unit providing inpatient treatment for paediatric patients in the province of Kuopio, a geographically defined area in eastern Finland. An exception is the regional hospital in Varkaus, located inside the area, which provides care for the inhabitants of that town. Children from Varkaus, as well as those living outside the province of Kuopio, were excluded from the analyses. The criteria for hospitalization in children with asthma attacks remained the same throughout the whole study period at the hospital. The authors' policy was to consider inpatient care if the obstruction did not improve after two doses of nebulized salbutamol given 30 min apart at the outpatient clinic.

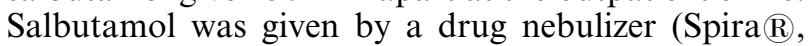
Spira, Respiratory Care Unit Ltd, Hämeenlinna, Finland) at a dose of $0.15 \mathrm{mg} \cdot \mathrm{kg}^{-1}$. According to the stepwise treatment policy used in the province of Kuopio $[15,20]$, cromones were prescribed as the firstline drugs until the early 1990s for children with asthma, and corticoids were restricted for those with severe symptoms or for those not controlled with cromones. By the mid 1990s, the treatment strategy was revised: inhalant treatment was primarily initiated with steroids, and after 6 months-1 yrs use the steroid was changed, if possible, to cromone $[15,21]$. Thereafter, the need for medication was re-evaluated at 6 months-1-yearly intervals.

The duration of hospital treatment was registered as 1 day if the patients were discharged on the same day as they had arrived, and as 2 days if there was an overnight stay. Re-admission was defined as two or more admissions for a patient during the same calendar year, and the annual re-admission rate, given as percentages, was calculated by dividing the number of re-admissions by all admissions of the same calendar year. Annual community-based demographic data for the child population in the province of Kuopio were obtained from the Finnish Official Bureau of Statistics. The population aged $<16$ yrs remained quite stable at $\sim 50,000$ during the 10 -yr study period. The annual number of total, first (i.e. the number of individual patients), and re-admissions, expressed as rates per 1,000 children of the same age group in the population, were analysed both as a whole group and further divided into three subgroups: $<2,2-4$, and $5-15$ yrs. The Social Insurance Institution (SII) maintains a nationwide register that provides data on drug prescribing in Finland. This SII register was used to obtain exact data on the purchases of prescribed inhaled cromones and steroids in the province of Kuopio from 1995 onwards.

Changes in the different admission rates at the population level were assessed by calculating the standardized incidence ratios (SIR) and related confidence intervals [22]. The nonparametric MannWhitney U-test was used to test the difference for age between the males and females, and the Fisher's exact probability test for the yearly re-admissions between the first and the last year of the study.

\section{Results}

In total 528 children, of whom $327(62 \%)$ were males and $201(38 \%)$ females, were admitted $(1,148$ admissions) during the study period. Males were admitted more often than females: $730(64 \%)$ versus $418(36 \%)$ admissions. The median age of the children (range) was $4.6(1.1-13.8) \mathrm{yrs}$ at the beginning of the study, diminishing to $2.5(0.4-14.1)$ yrs by the final year. At admission, the males were younger (median $3.4 \mathrm{yrs})$ than the females $(4.6 \mathrm{yrs})(\mathrm{p}<0.001)$. The median duration of inpatient treatment was 3.0 (1-31) days, increasing by 1 day during the study period. Only one child needed mechanical ventilation during these $10 \mathrm{yrs}$.

When all age groups were included, the total admission rates 1,000 children $^{-1}$ increased 2.3 -fold, from $1.2 \cdot 1,000^{-1}$ to $2.7 \cdot 1,000^{-1}$, during the 10 -yr study period $(\mathrm{p}<0.001)$. The first admissions, i.e. the number of individual patients, rose by $180 \%$. In contrast, readmissions declined from $28.1 \%$ to $8.7 \%(\mathrm{p}<0.001)$, with the sharpest decline occurring in the final year of the study (fig. 1).

The total number of anti-inflammatory drugs

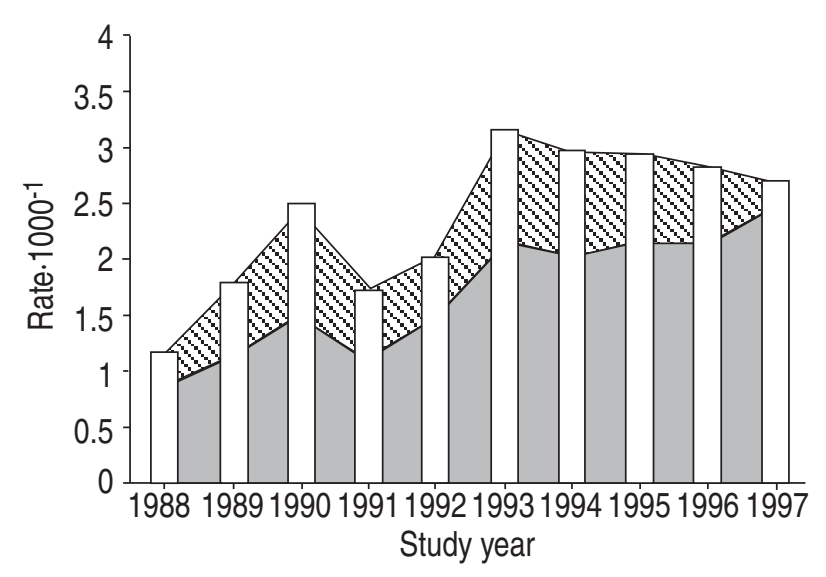

Fig. 1.-Hospitalization trends for paediatric asthma in the province of Kuopio from 1988-1997. $\square$ : total admissions; 1 : first admissions (i.e. the number of individual patients admitted); $\mathbb{\mathbb { V }}$ : re-admissions. All children admitted for asthma are included. 


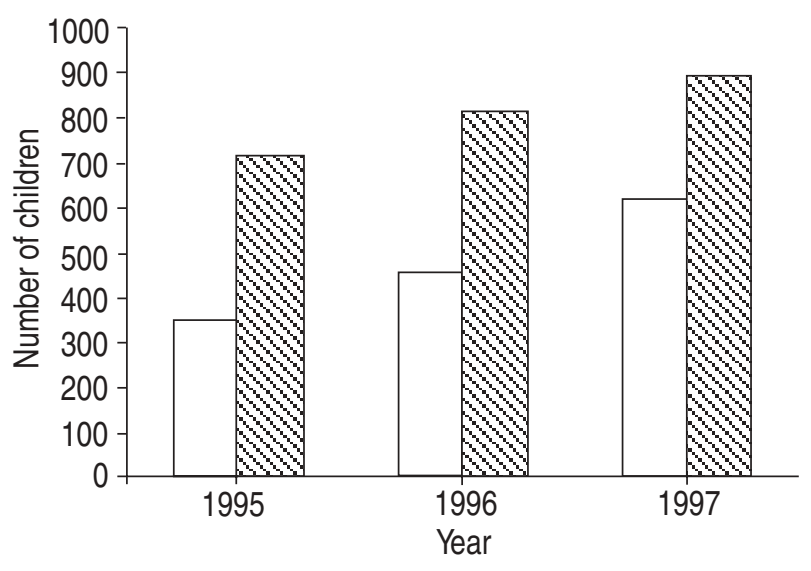

Fig. 2. - The prescription of anti-inflammatory drugs for asthma in children aged $\leqslant 15$ yrs in the province of Kuopio from 1995-1997. The numbers of prescribed inhaled steroids $(\square)$ and cromones $(\mathbb{\mathbb { N }})$ are presented separately. The differences between 1995-1997 were statistically significant $(\mathrm{p}<0.001)$ for both drugs. The data are based on the purchase of drugs for asthma in the area.

prescribed for asthma increased by $40 \%$ in the province of Kuopio from 1995-1997. The increase in inhaled cromones was $24 \%$ and that of steroids $73 \%$ (fig. 2).

\section{Children aged $<2$ yrs}

During the 10-yr follow-up period, the admission rate rose nine-fold: from $1.2 \cdot 1,000^{-1}$ to $10.5 \cdot 1,000^{-1}$ $(\mathrm{p}<0.001)$. A corresponding nine-fold increase was also observed for the number of first admissions. The re-admission rate varied from $13.2 \%$ to $59.3 \%$ of all admissions (fig. 3).

\section{Children aged 2-4 yrs}

The admission rate rose 2.4 -fold, from $3.0 \cdot 1,000^{-1}$ to $7.3 \cdot 1,000^{-1}$ in $1995(\mathrm{p}<0.001)$, decreasing thereafter

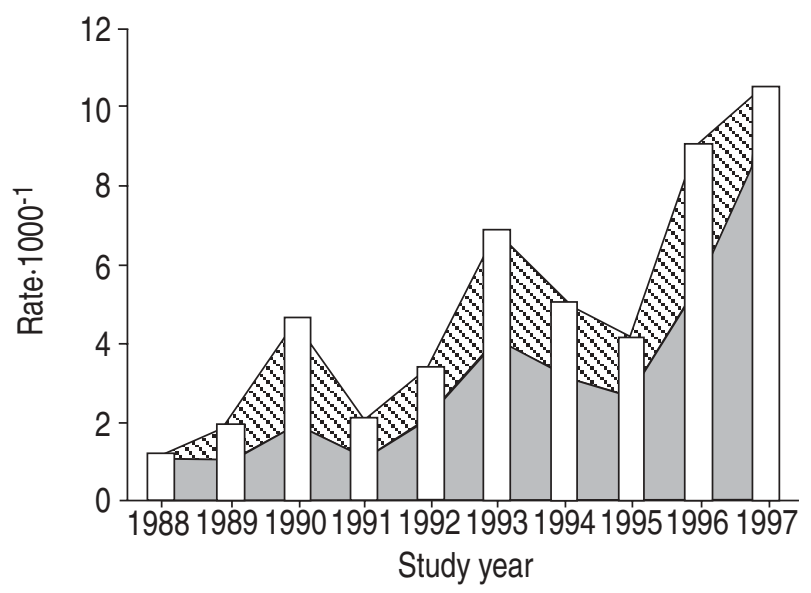

Fig. 3. - Hospitalization trends for asthma in children aged $<2$ yrs in the province of Kuopio from 1988-1997. $\square$ : total admissions; : first admissions (i.e. the number of individual patients

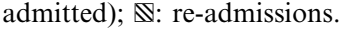

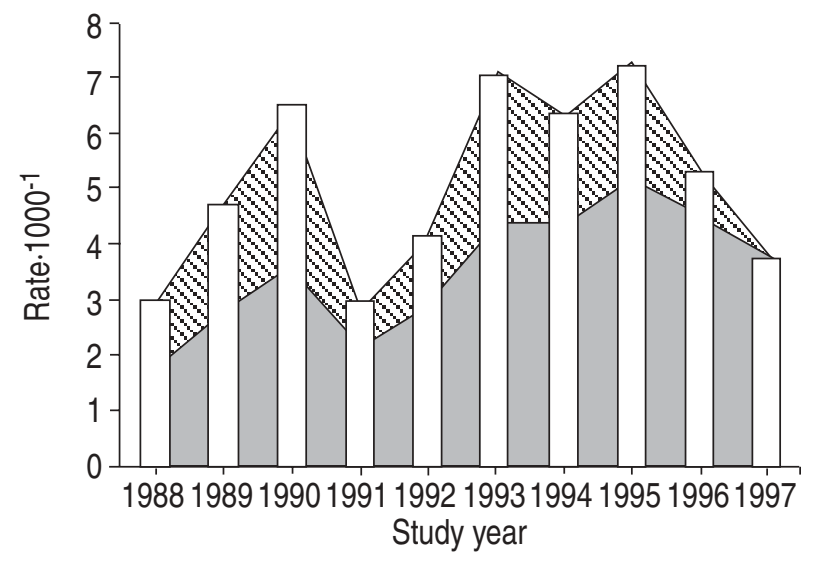

Fig. 4. - Hospitalization trends for asthma in children aged 2-4 yrs in the province of Kuopio from 1988-1997. $\square$ : total admissions; : first admissions (i.e. the number of individual patients admitted); $\mathbb{\mathbb { N }}$ : re-admissions.

to $3.9 \cdot 1,000^{-1}$ in $1997(\mathrm{p}<0.001)$. The number of first admissions rose by $113 \%$. Since 1995 , the readmissions have continually decreased, with no readmissions being reported in 1997 (fig. 4).

\section{Children aged 5-15 yrs}

The admission rate rose 2.4-fold between 1988-1994, from $0.7 \cdot 1,000^{-1}$ to $1.7 \cdot 1,000^{-1}(\mathrm{p}<0.001)$. During the last 3 yrs, however, the rate diminished by as much as $30 \%$, reaching $1.2 \cdot 1,000^{-1}$ in $1997(\mathrm{p}<0.05)$. The number of first admissions rose by $85 \%$. The re-admission rate varied from $9.8 \%$ to $42.6 \%$ of all admissions during the follow-up period (fig. 5).

\section{Discussion}

Hospitalization rates for acute exacerbations of asthma were studied during a $10-\mathrm{yr}$ period, from 1988-1997, in a geographically defined child population, in eastern Finland. During the study period, the

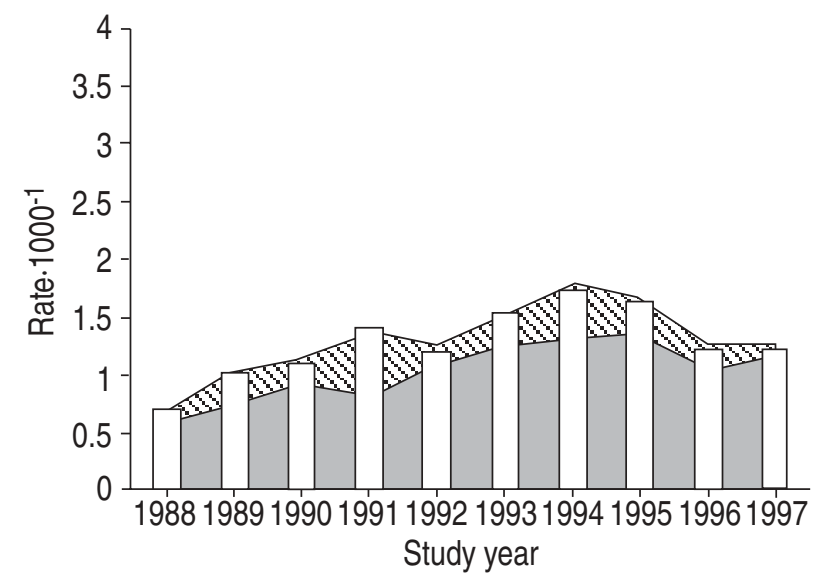

Fig. 5.- Hospitalization trends for asthma in children aged 5$15 \mathrm{yrs}$ in the province of Kuopio from 1988-1997. $\square$ : total admissions; : first admissions (i.e. the number of individual patients admitted); $\mathbb{\mathbb { Q }}$ : re-admissions. 
annual hospitalization rates increased 2.3-fold. The increase was most likely due to the increased number of patients, i.e. to first admissions. This study shows that the re-admission rates declined significantly in all study groups, except for those aged $<2$ yrs, during the study period. The reduction was clearest during the final years of the survey, which coincided with the increased use of inhaled steroids for paediatric asthma in the area.

Similar to previous findings, admissions increased, almost ten-fold during the $10 \mathrm{yrs}$, among children aged $<2$ yrs $[6,11,13]$. The median age of the hospitalized children decreased by 2 yrs during the study period [6]. Consistent with the findings of Norwegian studies [6,13], the results suggested that the onset of paediatric asthma has shifted to a younger age group. Conversely, annual admission rates are related to infection epidemics, especially in the youngest age groups [23]. The reasons for the peak in admissions among the youngest children in 1996 were, at least partly, due to the epidemics of respiratory syncytialand parainfluenza viruses. The awareness of asthma among patients and doctors may also have increased, which may explain why asthma diagnoses are made earlier. In other words, due to a better education and asthma awareness, the parents nowadays, to a greater extent than before, consult a doctor. In addition, sending a young child to hospital may be easier for general practitioners when compared to the 1980s. So, asthma may be diagnosed, and an anti-inflammatory treatment may be initiated, at an earlier age and phase of the disease than previously.

Among children aged $\geqslant 5$ yrs, hospital admission rates increased continually until 1994, but declined thereafter slowly. The decline coincided with the increased use of inhaled steroids in the authors' area (SII, unpublished data). In addition, the National Asthma Programme was published in Finland in 1994 [24]. The principal aim of this programme was to intensify outpatient treatment, in an attempt to lessen the need for inpatient treatment. Two other studies from the Nordic countries have shown a similar decrease in the number of hospital admissions, hospital days, and admitted patients, WenNERGReN et al. [12] reported a $50 \%$ decrease in admissions in Sweden until 1993, and JónAsson et al. [13] a slight decrease in Norway during the 1990s. Both observations can be attributed to active treatment with inhaled steroids at the population level.

Re-admission rates reflect the effectiveness of outpatient therapy, especially of regular therapy for asthma, perhaps better than other healthcare markers. A recently published Danish study showed that the risk of re-admissions for asthma fell by half among children aged 5-14 yrs during the elapsed 16 yrs, while the incidence of total admissions remained constant [19]. A similar trend has been shown in Norway, the re-admissions decreased, though the first admissions increased [13]. Similarly, Senthilselvan [25] in Canada reported that re-admissions for asthma do not explain the increasing trend in admissions for asthma in children. The decreasing number of re-admissions also reported in the present study probably reflected the improved treatment balance of asthma following the introduction and more active usage of inhaled steroids. The decrease in readmissions explains the decrease in total admissions, in an era during which the increase in first admissions has paralleled the increasing prevalence of asthma.

In the present study, the median duration of hospital stay was only 3 days, increasing however, by 1 day during the study period $[16,26]$. In other recent Scandinavian studies, the length of hospital stay diminished significantly over the last two decades $[6,12,19]$. Likewise, in a Finnish 20 -yr nationwide study, the duration of hospital stay decreased from $>1$ week in 1976 to the current 3 days in 1995 [11]. The short duration of hospital stay, as well as the fact that only one child needed mechanical ventilation, reflected the mild nature of asthma in the authors' area. An early detection of asthma and active usage of anti-inflammatory drugs has, most likely, also contributed to the mild nature of paediatric asthma in Finland [11].

The present $10-\mathrm{yr}$ study was retrospective, based on the computerized register and medical records of the authors' hospital. The long follow-up period is essential to minimize yearly random variation. The risk of systematic errors is higher in retrospective analyses than in prospective ones; for example, the diagnostic criteria of asthma may have changed during the study period. To minimize these risks, the patients were screened from the register not only by the diagnosis of asthma, but also by obstructive bronchitis. The same investigator reviewed systematically all individual medical records and decided, regardless of the recorded diagnoses, whether the criteria of asthma and acute exacerbation were fulfilled or not. The hospital is the only unit providing inpatient treatment for this geographically defined child population, which guarantees the representativeness of the study. However, the few patients from the area treated in other hospitals in Finland were not included. In the majority of cases, asthma diagnosis was based on at least the third doctor-diagnosed asthmatic attack. Both factors may underestimate rather than overestimate the admission figures at the population level. Conversely, due to the simple inclusion criteria in the study, even young recurrently wheezing children were interpreted as having asthma, minimizing the bias caused by age. Unfortunately, reliable information for comparison of SII data was not available on the consumption of antiinflammatory drugs in the area until 1995. However, the hospital-based data, gathered mainly from outpatients, suggested that steroids were clearly used less before the year 1995 [20, 27].

To conclude, the results suggest that the rise in asthma prevalence is associated with the increased need for hospital treatment, but to a lesser degree than might be expected. The diminished need for hospital care among pre- and school-aged children was due to decreased re-admissions. The early onset of and increased use of inhaled steroids is the most likely reason for these beneficial observations. The stepwise treatment policy guarantees the effectiveness of therapy and minimizes the harmful effects of inhaled steroids. 
Acknowledgements. The authors would like to thank P. Halonen, for statistical advice and K. Pennington for the language revision.

\section{References}

1. Remes S. Epidemiology of asthma and allergy at school age. Dissertation. Kuopio University Publications D. Medical Sciences 141. Kuopio University Printing Office, Kuopio, 1998.

2. Burney PGJ, Chinn S, Rona RJ. Has the prevalence of asthma increased in children? Evidence from the national study of health and growth 1973-86. BMJ 1990; 300: 1306-1310.

3. Burr ML, Butland BK, King S, Vaughan-Williams E. Changes in asthma prevalence: two surveys 15 years apart. Arch Dis Child 1989; 64: 1452-1456.

4. Skjonsberg $\mathrm{OH}$, Clench-Aas $\mathrm{J}$, Leegaard $\mathrm{J}$, et al. Prevalence of bronchial asthma in schoolchildren in Oslo, Norway. Comparison of data obtained in 1993 and 1981. Allergy 1995; 50: 806-810.

5. Kun HY, Oates RK, Mellis CM. Hospital admissions and attendances for asthma - a true increase? Med J Aust 1993; 159: 312-322.

6. Carlsen K-H. Epidemiology of childhood asthma. Eur Respir Rev 1994; 17: 5-9.

7. Wickman M, Farahmand BY, Persson PG, Pershagen G. Hospitalization for lower respiratory disease during $20 \mathrm{yrs}$ among under $5 \mathrm{yr}$ old children in Stockholm County: a population based survey. Eur Respir J 1998; 11: 366-370.

8. Priftis K, Anagnostakis J, Harokopos E, Orfanou I, Petraki M, Saxoni-Papageorgiou P. Time trends and seasonal variation in hospital admissions for childhood asthma in the Athens region of Greece: 1978-88. Thorax 1993; 48: 1168-1169.

9. Hyndman SJ, Williams DRR, Merrill SL, Lipscombe JM, Palmer CR. Rates of admission to hospital for asthma. BMJ 1994; 308: 1596-1600.

10. Strachan DP, Anderson HR. Trends in hospital admission rates for asthma in children. BMJ 1992; 304: 819-820.

11. Malmström K, Korhonen K, Kaila M, et al. Acute childhood asthma in Finland: a retrospective review of hospital admissions from 1976 to 1995. Pediatr Allergy Immunol 2000; 11: 236-240.

12. Wennergren $\mathrm{G}$, Kristjánsson $\mathrm{S}$, Strannegård I-L. Decrease in hospitalization for childhood asthma with increased use of anti-inflammatory treatment, despite an increase in the prevalence of asthma. J Allergy Clin Immunol 1996; 97: 742-748.

13. Jónasson G, Lodrup Carlsen KC, Leegard J, Carlsen $\mathrm{K}-\mathrm{H}$, Mowinckel P, Halvorsen KS. Trends in hospital admissions for childhood asthma in Oslo, Norway, 1980-1995. Allergy 2000; 55: 232-239.

14. Östergaard PA, Nielsen JP. Medical treatment of asthmatic children before referral to a clinic for allergy. A comparison between the periods 1979-83 and 1988-91. Allergy 1994; 49: 390-392.

15. Warner JO, Naspitz CK, Cropp GJA. National Heart, Lung and Blood Institute and World Health Organization: Asthma management and prevention 1995. Third international pediatric consensus statement on the management of childhood asthma. Pediatr Pulmonol 1998; 25: 1-17.

16. Adams RJ, Fuhlbrigge A, Finkelstein JA, et al. Impact of inhaled antiinflammatory therapy on hospitalization and emergency department visits for children with asthma. Pediatrics 2001; 107: 706-711.

17. Paterson NA, Peat JK, Mellis CM, Xuan W, Woolcock AJ. Accuracy of asthma treatment in schoolchildren in NSW, Australia. Eur Respir J 1997; 10: 658-664.

18. Donahue JG, Weiss ST, Livingston JM, Goetsch MA, Greineder DK, Platt R. Inhaled steroids and the risk of hospitalization for asthma. JAMA 1997; 277: 887891.

19. Bisgaard H, Moller H. Changes in risk of hospital readmission among asthmatic children in Denmark, 1987-93. BMJ 1999; 319: 229-230.

20. Korppi M, Remes K. Asthma treatment in schoolchildren: lung function in different therapeutic groups. Acta Paediatr 1996; 85: 190-194.

21. Kannisto S, Voutilainen R, Remes K, Korppi M. Efficacy and safety of inhaled steroid and cromone treatment in school-aged children. A randomised pragmatic pilot study. Pediatr Allergy Immunol 2002 (in press).

22. Gardner MJ, Altman DG. Confidence intervals for standardised ratios and rates. Statistics with Confidence. London, British Medical Journal, 1989; pp. 59-60.

23. Phelan PD, Landau LI, Olinsky A. Epidemiology of acute respiratory infections. Respiratory Illness in children. London, Blackwell scientific publications, 1991; pp. 24-46.

24. Asthma Programme in Finland 1994-2004. Ministry of Social Affairs and Health. Clin Exp Allergy Suppl 1996; 1: 1-24.

25. Senthilselvan A. Effect of readmissions on increasing hospital admissions for asthma in children. Thorax 1995; 50: 934-936.

26. Minkovitz C, Andrews J, Serwint J. Rehospitalization of children with asthma. Arch Pediatr Adolesc Med 1999; 153: 727-730.

27. Korppi M, Kuikka L, Remes K. Preventive therapy for asthma in children; a 9-year experience in Eastern Finland. Eur Respir J 1995; 8: 1318-1320. 